Self-healing materials Fundamentals, Design Strategies, and Applications

Swapan Kumar Ghosh (editor)

Wiley · 2009 · 306 pp

ISBN: 978-3-527-31829-2

$£ 105.00 / € 126.00 / \$ 175.00$

The book covers self-healing concepts for all important material classes and their applications: polymers, ceramics, non-metallic and metallic coatings, alloys, nanocomposites, concretes and cements, as well as ionomers. As the first book in this swiftly growing research field, it is of great interest to readers from many scientific and engineering disciplines, such as physics and chemistry, civil, architectural, mechanical, electronics and aerospace engineering.

\section{of}

\section{A laboratory course in biomaterials}

\section{Wujing Xian}

CRC Press $\cdot 2009 \cdot 216$ pP

ISBN: 978-1-4200-7582-2

$£ 36.00 / € 41.00 / \$ 59.95$

The field of biomedical engineering has vastly expanded in the past two decades, as reflected in the increased number of bioengineering and biomaterials programs at universities. The growth of this area has outpaced the development of laboratory courses that allow students hands-on experience, since the barriers involved in creating multidisciplinary biomaterials laboratory courses are high. A laboratory course in biomaterials provides a new teaching tool that is comprehensive in scope and current in its perspective.

$\checkmark$

\section{Advances in polymer processing \\ From macro to nano scales}

S Thomas, and W Yang (eds.) Woodhead Publishing Ltd · 2009 · 752 pp ISBN: 978-1-84569-396-1 $£ 175.00 / € 220.00 / \$ 330.00$

Processing techniques are critical to the performance of polymer products which are used in a wide range of industries. Advances in polymer processing: From macro to nano scales reviews the latest advances in polymer processing, techniques and materials.

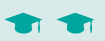

$$
\begin{array}{lll}
\text { Expert } & \text { Graduate } \\
\text { Undergraduate } & \text { वा }
\end{array}
$$

\title{
Materials and the Environment: Eco-informed material choice
}

\author{
This book is the first devoted exclusively to the environmental \\ aspects of materials, a core subject area for undergraduate \\ students in several engineering disciplines
}

Marshall Stoneham | University College London | ucapams@ucl.ac.uk

The first challenge of climate change is convincing sceptics that it is real.The second challenge is convincing the press that solutions are not trivial. The third challenge is ensuring that the basics are understood. Global warming is a problem even without $\mathrm{CO}_{2} ; \mathrm{CO}_{2}$ is a problem even without global warming; water shortage and landfill are distinct but real problems. A fourth challenge is educating us all, since understanding is surely the best way to make difficult changes acceptable.

Michael Ashby set a new trend in materials studies with his "materials maps" that showed, for example, the systematic ways that a wide range of materials responded to applied stresses. His insight was that suitable presentation let one see the broad picture in a very practical way, and led to articles, books, and software designed to aid materials selection. His initiative continued with studies of design, where materials are to be selected both for performance (with ideas like figures of merit for applications), and for factors like appearance.

This book is timely and important, focussing on the identification and systematic analysis of how materials decisions have environmental consequences. Ashby reminds readers that, when considering some series of actions, they should compare them with alternatives. Anyone with a favourite idea should have the honesty to consider the whole cycle of steps needed to implement it. For energy generation, one should know carbon costs for site clearance, fabrication, connecting supply to user, and finally clearing the site. One should know credible lifetimes of equipment, and likely hours per day the facility will provide energy. One should know the difference between rated power and what might be delivered. One should know the difference between real cost and subsidised cost. One should understand the carbon cycle, once taught in schools, now usually edited to suit the views of the speaker or journalist. And - which is where this book is especially good - one should have the capability to assess new ideas, or the effects of changes in life style or in the international scene.

What Michael Ashby has done is (as he describes it) create a "toolbox." It is, of course, more than that. The opening chapters look at resource consumption, and at drivers that range from lifestyle to global population.
A later chapter addresses the way legislation affects materials choices and the ways they can be used. He then looks at the life cycles of various materials and equipment, and they was these interconnect. An important chapter asks about equipment that has reached the end of its first life, whether due to fashion, wear-out, and so on: is the equipment a problem to be disposed of, or is it a resource that might be used in other applications? These, plus chapters on ecodata (where he rightly asks about its accuracy) lead to discussions of eco-informed materials strategies, auditing,
and sustainability. Happily, these are and sustainability. Happily, these are much more than the facile comments one reads too often (for example, the real examination question "Wasting less electricity would be good for the Australian environment. Explain why"). Some of the key ideas will be new to many people, like the embodied energy in a material, such as aluminium or a polycarbonate. But these figures, with $\mathrm{CO}_{2}$ footprint, water use in production, and so on, must underpin proper strategies for the future health of our
Michael F. Ashby 前

Michael F Ashby (author) Materials and the Environment: Eco-informed material choice Elsevier/Butterworth-Heinemann • $2009 \cdot 400$ pp ISBN 978-1-85617-608-8 • \$69.95 / €47.95 / £37.99

climate. I have oversimplified the discussion, of course. But the book is admirably clear, and its thoughtful approach is much more likely to be a positive influence than assertively sensationalist writers. He does not insist on specific solutions (like the journalists who discuss the green credentials of cork versus plastic wine stoppers) but gives the reader the tools to look at options and compare their environmental consequences quantitatively. As an aid to this, there are some extremely helpful pages of data on different common materials - metals and alloys, ceramics, polymers, and a few others.

This book, the author says, is primarily for undergraduate students of Engineering and Materials Science. It will be excellent for this purpose. Much of it would be excellent for science teachers in sixth forms, and perhaps even better for those who set national science examinations. If only it could be read by the politicians and civil servants who frame policy, or by anyone who believes they have excellent green credentials. 